
IN THE VEDDER SAND ROUND MOUNTAIN FIELD, CALIFORNIA FINAL REPORT DOE Grant NO. DE-FG26-00BC15258

July 5, 2001

Prepared for:

Macpherson Oil Company 2716 Ocean Park Boulevard, Suite 3080 Santa Monica, California 90405

Prepared by: David W. Chenot, P.E. WZI Inc. 4700 Stockdale Highway, Suite 120 Bakersfield, California 93309 


\section{DISCLAMER}

This report was prepared as an account of work sponsored by an agency of the United States Government. Neither the United States Government nor any agency therefore, nor any of their employees, makes any warranty, express or implied, or assumes any legal liability or responsibility for the accuracy, completeness, or usefulness of any information, apparatus, product, or process disclosed, or represents that its use would not infringe privately owned rights. Reference herein to any specific commercial project, process, or service by trade name, trademark, manufacture, or otherwise does not necessarily constitute or imply its endorsement recommendations, or favoring by the United States Government or any agency thereof. The views and opinions of authors expressed therein do not necessarily state or reflect those of the United States Government or any agency thereof. 


\title{
SHORT RADIUS LATERAL DRILLING \\ IN THE VEDDER SAND \\ ROUND MOUNTAIN FIELD, CALIFORNIA
}

\begin{abstract}
Horizontal wells appear to offer many benefits to the type of steam drive project in operation in the Round Mountain field, California. This is a crestal steam flood, injecting steam at the top of the homoclinal structure, and driving oil to downstructure wells. To evaluate horizontal drilling, a 3-D reservoir simulation model study was performed, and a short radius lateral was drilled from an existing producer. Problems encountered in setting the plug and making the turn resulted in the bore hole being beneath the target zone, requiring a higher hole angle than planned to return to the target. The Rotary Steerable System used in the drilling process was not able to build angle above 90 degrees in the soft Vedder sand, and eventually a fish was lost in the hole, resulting in abandonment of the sidetracking effort.

Subsequently a conventional intermediate radius horizontal well was successfully drilled with a 134 meter (440 foot) horizontal section. After clean-up, the well demonstrated a high productivity index of 3.2 cubic meters per day per kilopascal $(140 \mathrm{~B} / \mathrm{D} / \mathrm{psi})$, and is currently producing 27 cubic meters per day (170 B/D) oil, and 659 cubic meters per day (4143 B/D) water.
\end{abstract}




\section{TABLE OF CONTENTS}

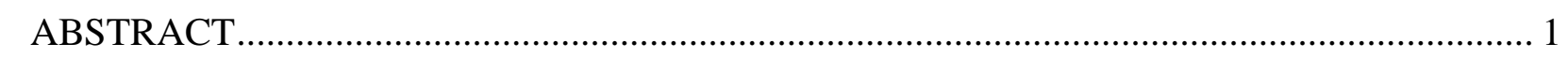

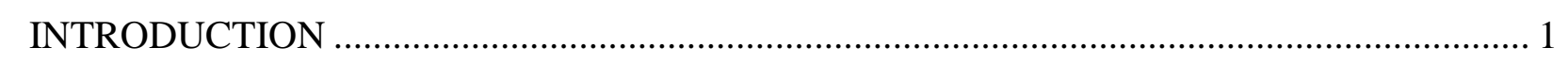

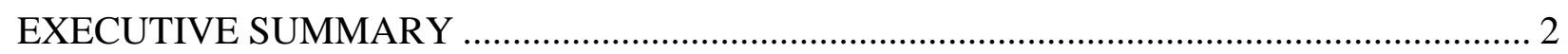

EVALUATION OF HORIZONTAL WELL DRILLING....................................................... 3

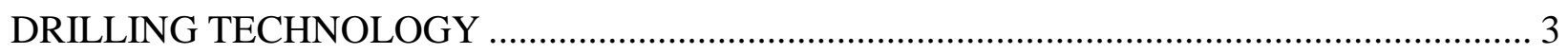

HISTORY OF TOOL DEVELOPMENT ...................................................................... 4

THE "ROTARY STEERABLE SYSTEM" ............................................................. 5

SELECTION OF SHORT RADIUS LATERAL WELL .................................................. 5

DRILLING HISTORY .............................................................................................. 5

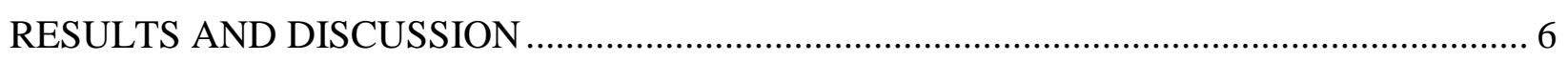

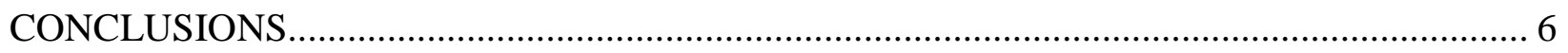

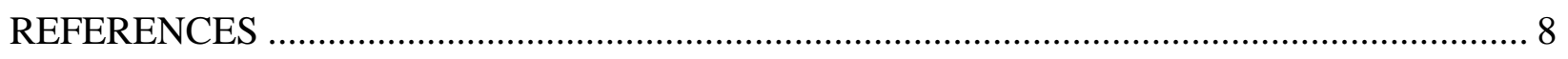

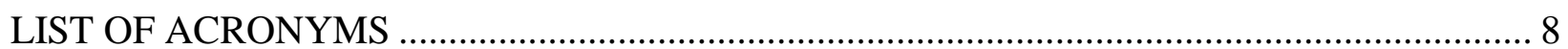

\section{LIST OF GRAPHICAL MATERIALS}

Exhibit $1 \quad$ Round Mountain Oil Field Orientation Map

Exhibit 2 Round Mountain Unit Thermal Development Plan

Exhibit 3 Conceptual Drawing - Horizontal Well

Exhibit 4 Well 18 \#93 Proposed Wellpath

Exhibit 5 Well 18 \#93 Proposed vs Actual Wellpath 


\section{Introduction}

The Round Mountain Oil Field is located on the east side of the San Joaquin Valley in Kern County, California, about ten miles northeast of Bakersfield. Exhibit I is a location map for the field. The Round Mountain Field was discovered in 1927, and was developed in stages, with over 230 wells drilled.

Three stratigraphic units have contributed to the production of the field: The Jewett, the Pyramid Hill and the Vedder. Of the three, the Vedder has been the most prolific, producing over 50 million barrels of oil. There is a strong water drive in the field, and prior to thermal operations water cut exceeded 99 percent.

The development plan for the Round Mountain Field is patterned after the successful Mount Poso steamflood project, commenced in 1971 and now abandoned. The Mount Poso field is located six miles to the northwest of Round Mountain, and the Vedder reservoir is analogous to the Vedder in Round Mountain in many ways.

The flooding concept employed at Mount Poso and being used at Round Mountain calls for injection of steam updip, near the bounding fault, while simultaneously withdrawing water and oil downdip. The result is a steam front that slowly sweeps the updip area and mobilizes the oil, which migrates by gravity to strategically placed producing wells. A map of the thermal development plan status is shown on Exhibit 2. 


\section{Executive Summary}

Horizontal wells have a high potential for increasing oil recovery in shallow dipping line drive steamfloods. They offer the advantage of a long producing interval in the oil bank, and are located in a position to recover hot oil moving downstructure by gravity drainage.

A 3-D simulation model study was run using CMG's STARS thermal model, and showed that a 122 meter (400 foot) horizontal well should produce up to 64 cubic meters per day of oil (400 $\mathrm{B} / \mathrm{D})$ when the heated oil bank hits the well.

To test this concept in the Round Mountain Unit, a relatively new and inexpensive drilling method was employed. This method, called "short radius lateral" drilling, consists of exiting an existing wellbore at or near the top of the target formation, making a 10.7 to 18.3 meter (35 to 60 foot) radius turn, and drilling a 122 to 213 meter (400 to 700 foot) horizontal lateral.

The short radius lateral technology was tried in an existing well in the Round Mountain Field, but the well could not be completed as designed due to slippage below the target formation and inability to build hole angle in the soft formation.

Subsequently a conventional intermediate radius well was drilled and successfully completed. 


\section{Evaluation of Horizontal Well Drilling}

There are several perceived benefits to be derived from horizontal wells in the Round Mountain Thermal Project. These include higher oil rates and greater oil recoveries than vertical wells, higher ultimate recovery efficiency, and potentially lower development costs due to less dense development. Higher oil rates are expected because of the greater length of borehole open to the formation, and higher recovery efficiency is due to suppressing steam coning and cusping into the producing wells. Furthermore, by locating the horizontal well path near the bottom of the producing formation, it will be in an optimum position to intercept oil migrating downward by gravity drainage. A conceptual drawing of a horizontal wellbore ahead of the steam bank is shown on Exhibit 3.

A 3-D simulation model study was made of the Round Mountain Field using CMG's STARS thermal model. The model confirmed that a suitably placed horizontal well would produce at rates up to 64 cubic meters per day ( $400 \mathrm{~B} / \mathrm{D})$ of oil.

\section{Drilling Technology}

Two different drilling methods were considered, with different methods, costs, and strategies for utilization. One is a long reach, intermediate radius well (IRW) which is drilled from a surface location, kicks off above the top of the Vedder sand, and traverses from 610 to 914 meters $(2,000$ to 3,000 feet) horizontally. The other is a shorter lateral drilled from an existing well bore. This technique, called a short radius well (SRW), involves recovering the liner, kicking off with a short 10.7 to 18.3 meter (35 to 60 foot) radius completely within the Vedder sand, and drilling 122 to 213 meters (400 to 700 feet) laterally.

During the past decade, the oil and gas industry witnessed a steady increase in the use of horizontal drilling to enhance well productivity. As the database of horizontal projects has grown, operators have developed a better understanding of how and where horizontal wells should be utilized and which technology is best for a given application. The implementation of laterals in mature fields requires substantial cost reductions over the methods most often used for drilling horizontal wells. Because of this, the use of short radius horizontal reentry and completion technology to reactivate and rejuvenate existing fields is growing rapidly. 


\section{History of Tool Development}

Amoco Corporation has developed a short radius lateral drilling system that can offer substantial cost savings over conventional mud motor technology.

The need for a reliable reduced-cost drilling system that uses the equipment and cost structures associated with workover and repair services provided the impetus for the development of this technology.

In 1989, Amoco initiated a project to develop a short radius lateral drilling system. The development criteria consisted of four main objectives:

- Develop a system low in cost to manufacture, repair and, operate;

- develop a system that will drill a predictable and consistent radius of curvature in a desired direction;

- develop a system capable of operating from a service rig using a power swivel; and

- develop a system capable of working inside $11.43 \mathrm{~cm}$ ( $4.5 \mathrm{inch})$ casing.

Following development of the prototype tools, more than 200 test wells were drilled at Amoco's Catoosa Test Facility near Tulsa, Oklahoma. Following testing, the technology was taken to the field where it was used to drill several wells at Amoco's Levelland Unit. These initial test wells provided the basic capability to install lateral drain holes at a reasonable cost with top drive power swivel and workover rig.

The system, which has become known as the "Rotary Steerable System", has been tested, developed, and improved to the point where it is a successful and commercially viable technology. Since the first quarter of 1995, more than 100 wells have been drilled with the Rotary Steerable System. 


\section{The "Rotary Steerable System"}

The system is purely mechanical. There are no mud motors or expensive electronics downhole. In comparison to typical mud motor systems, overall total well costs can be considerably lower. Simple parts maintenance of the downhole assemblies translates into quick on-site repair time eliminating costly standby time charges associated with shop repairs. Spare parts are readily available and cost pennies on the dollar compared to other systems. Inspection and repair charges are greatly reduced and lost-in-hole liability is less than a mud motor assembly.

In this horizontal drilling system, bit rotation is derived from the power swivel with continuous pipe rotation throughout the curve and lateral drilling process.

The Rotary Steerable System is capable of drilling three hole sizes:

- $\quad 9.84 \mathrm{~cm}$ (3.875 inch) to work inside $11.43 \mathrm{~cm}$ (4.5 inch) casing;

- $11.43 \mathrm{~cm}$ (4.5 inch) to work inside $13.97 \mathrm{~cm}$ (5.5 inch) casing; and

- $15.56 \mathrm{~cm}$ (6.125 inch) to work inside $17.78 \mathrm{~cm}$ (7 inch) casing or larger.

Radius of curvature ("ROC") generally ranges from 9.1 to 30.5 meters (30 to 100 feet); larger radii can be drilled when required. Lateral departures have typically been 91 to 305 meters(300 to 1,000 feet). While longer laterals are possible, the most frequently drilled wellpath has combined a radius of 10.7 meters ( 35 feet) with a 152 meter (500 foot) lateral.

Multiple laterals can be drilled in opposing directions or in the same direction, landing at the same true vertical depth ("TVD") or at varying TVD's.

\section{Selection of Short Radius Lateral Well}

The decision to drill a short radius lateral from an existing well (SRW) was made because it could be drilled more cheaply than an IRW, used existing wells, and had future application for developing the lower, less permeable portion of the Vedder sand.

With this in mind, well Section $18 \# 93$ was selected as the test well for drilling a lateral. The Vedder sand falls roughly into two permeability regimes, an upper sand with permeability of five to six Darcies, and a lower sand with permeability of approximately one Darcy. These are called the Coarse Grain Sand and the Fine Grain Sand, respectively. The Coarse Grain Sand is the only responding portion of the reservoir to date. The drilling plan was to kick off the well just below the casing shoe, and using a 16.8 meter (55 foot) radius, to stay in the Coarse Grain Sand unit for approximately 244 meters ( 800 feet) laterally with a 93 to 94 degree sail angle. A schematic of the proposed well course is shown on Exhibit 4.

\section{Drilling History}

Work began July 17, 2000 for the Section 18 \# 93 Short Radius Lateral workover. Several attempts were made to get a competent cement plug without mud contamination, and one was finally obtained. A $11.43 \mathrm{~cm}(4.5 \mathrm{inch})$ pilot hole was drilled from the dressed-off depth of 651 
meters $(2,135$ feet) to 654 meters (2,146 feet), 1.5 meters (five feet) below the $21.91 \mathrm{~cm}(8-5 / 8$ inch) casing shoe. The 16.8 meter (55 foot) Curve Drilling Assembly (CDA) was run and the tool oriented at 337 degrees. Drilling proceeded, but the well did not actually begin to kick off from vertical until 658 meters (2,160 feet), slipping approximately 4.57 meters (15 feet). This slippage of the kick off point caused the curve to enter the Fine Grain Sand: However, at a 98 degree final build, it would have been possible to re-enter the Coarse Grain Sand within 46 meters (150 feet) of departure from the kick-off point.

The total vertical depth (TVD) of the Coarse/Fine grain boundary is 670.6 meters $(2,200$ feet). The hole was drilled to 683.4 meters (2,242 feet) measured depth (MD), 674.8 meters (2,214 feet) TVD, showing it was still in the Fine Grain Sand. Surveys indicated that the tool was not building angle beyond 90 degrees. The tool was pulled, repaired and rerun to 683.4 meters (2,242 feet) MD. Drilling continued to 695.9 meters (2,283 feet) MD, 676 meters (2,218 feet) TVD with a departure of 28 meters (92 feet). Again the tool was not responding, and the inclination was still at or below the 90 degree mark keeping it in the Fine Grain Sand unit. At this point the 16.8 meter ( 55 foot) CDA was pulled, and a more aggressive 10.7 meter (35 foot) CDA run. The well was drilled from 695.9 to 705.6 meters (2,283 to 2,315 feet) MD, 676 meters (2,218 feet) TVD, 86 degree inclination, 337.5 degree azimuth, 37.3 meters (122.3 feet) departure using this tool, again not building beyond the 90 degree mark. The proposed and actual well paths are shown on Exhibits 4 and 5. A fish was subsequently lost in the hole, and the sidetracking abandoned. The well was completed above the fish with a $8.89 \mathrm{~cm}(31 / 2 \mathrm{inch})$ liner.

Unfortunately the failure of the lateral drilling attempt did not help answer the questions of the value of horizontal drilling in the Round Mountain Thermal Project. Subsequently an intermediate radius horizontal well was drilled from the surface with a mud motor in nearly the same location. This well was completed with $11.4 \mathrm{~cm} \mathrm{(4} \mathrm{1/2} \mathrm{in)} \mathrm{slotted} \mathrm{liner} \mathrm{in} \mathrm{a} 134$ meter (440 foot) horizontal section. After clean-up, the well is producing 27 cubic meters per day (170 B/D) oil, and 659 cubic meters per day $(4,143 \mathrm{~B} / \mathrm{D})$ water, with a high productivity index of 3.2 cubic meters per day per kilopascal (140 B/D per psi).

\section{Results and Discussion}

Torch Drilling Services LLC, the contractor, believes the age of the test well and number of years it had produced probably altered the near wellbore stability by creating a large cavity in the formation around the wellbore. This in turn affected the ability to get a solid cement plug and to kickoff at the proposed depth, causing the CDA to slide approximately 4.6 meters (15 feet) before establishing contact points. Once the CDA was locked in place, it was able to make the prescribed turn, and although the hole came in approximately 5.5 meters (18 feet) low, it was very near the target azimuth at the end of the curve. The inability of the tool to build hole angle greater than $90^{\circ}$ degrees appears to be due to the unconsolidated nature of the formation.

\section{Conclusions}

In view of the number of successful applications of the Rotary Steerable System,one failure is not surprising, and does not condemn the system. However, the operator believes that the 
Vedder sand is not a good target for Rotary Steerable System tools because of its unconsolidated nature.

The successful completion of an IRW with a high productivity index supports the concept that horizontal wells can produce at high rates in the Vedder Formation. The well is in a favorable position to recover maximum oil rates when the hot oil bank reaches the well. 


\section{REFERENCES}

Torch Drilling Services LLC, sales brochure.

LIST OF ACRONYMS AND ABBREVIATIONS:

IRW Intermediate Radius Well

SRW Short Radius Well

ROC Radius of Curvature

TVD True Vertical Depth

MD Measured Depth

CDA Curve Drilling Assembly 
$\underline{\text { EXHIBITS }}$ 


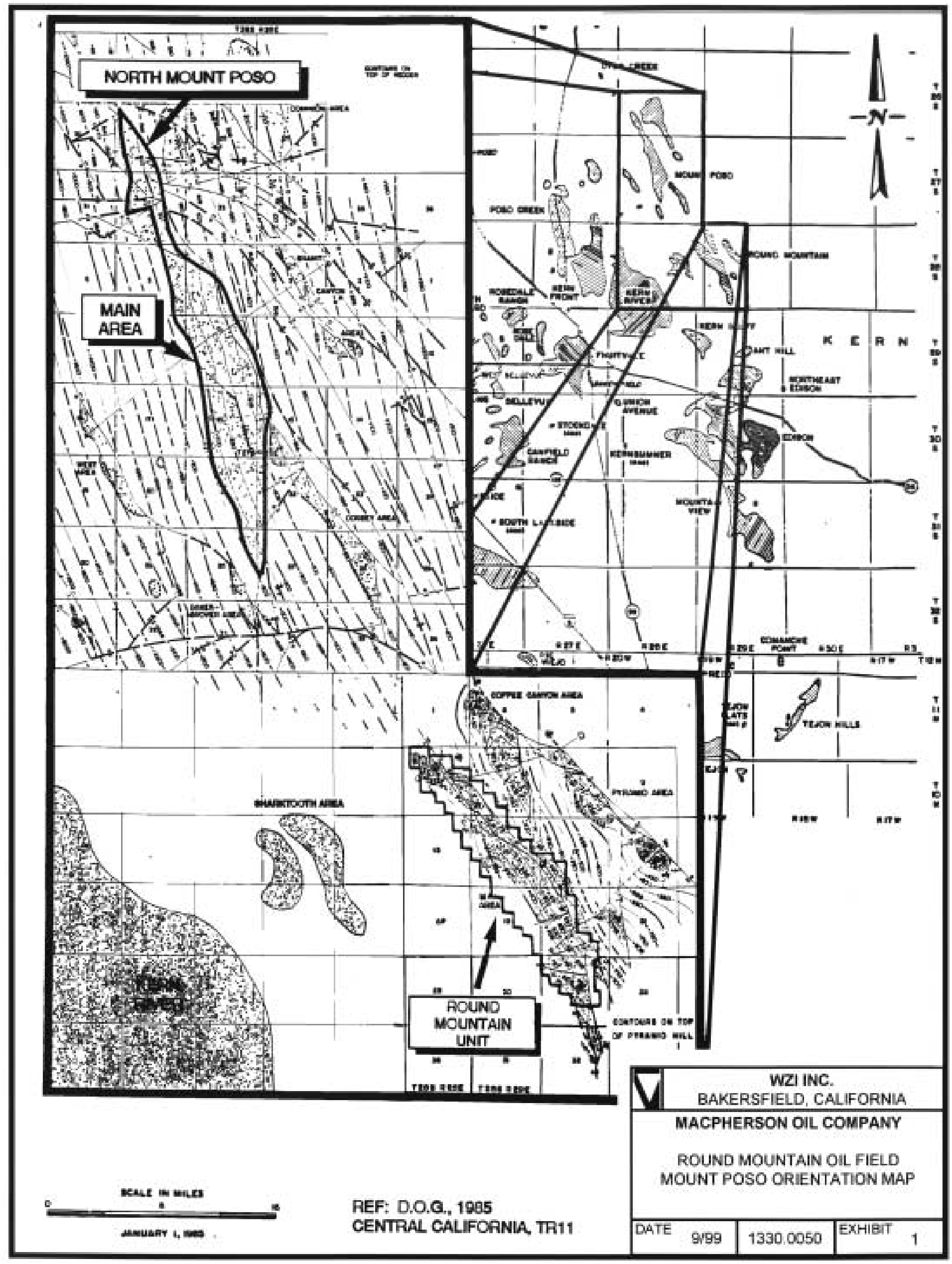




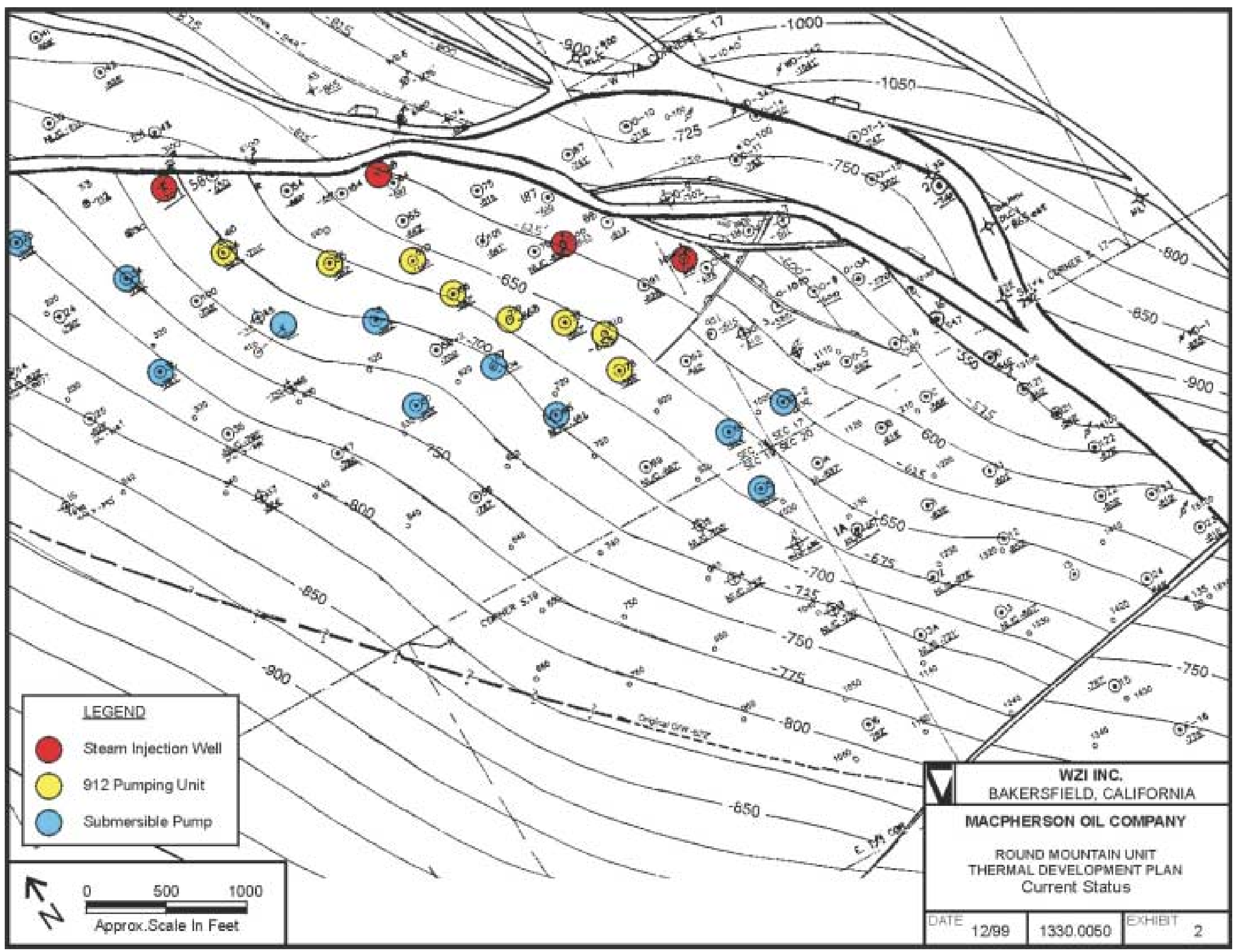




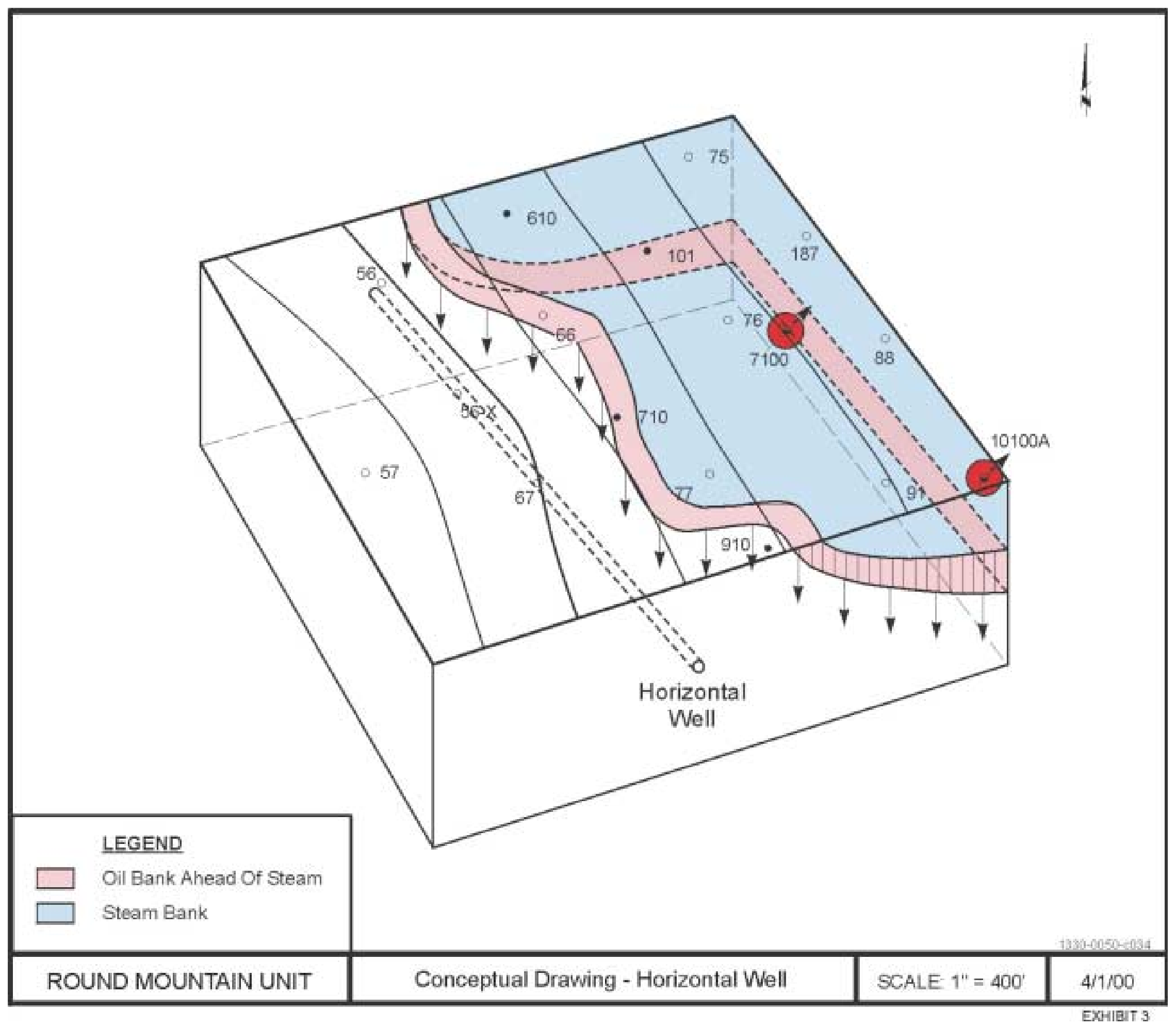




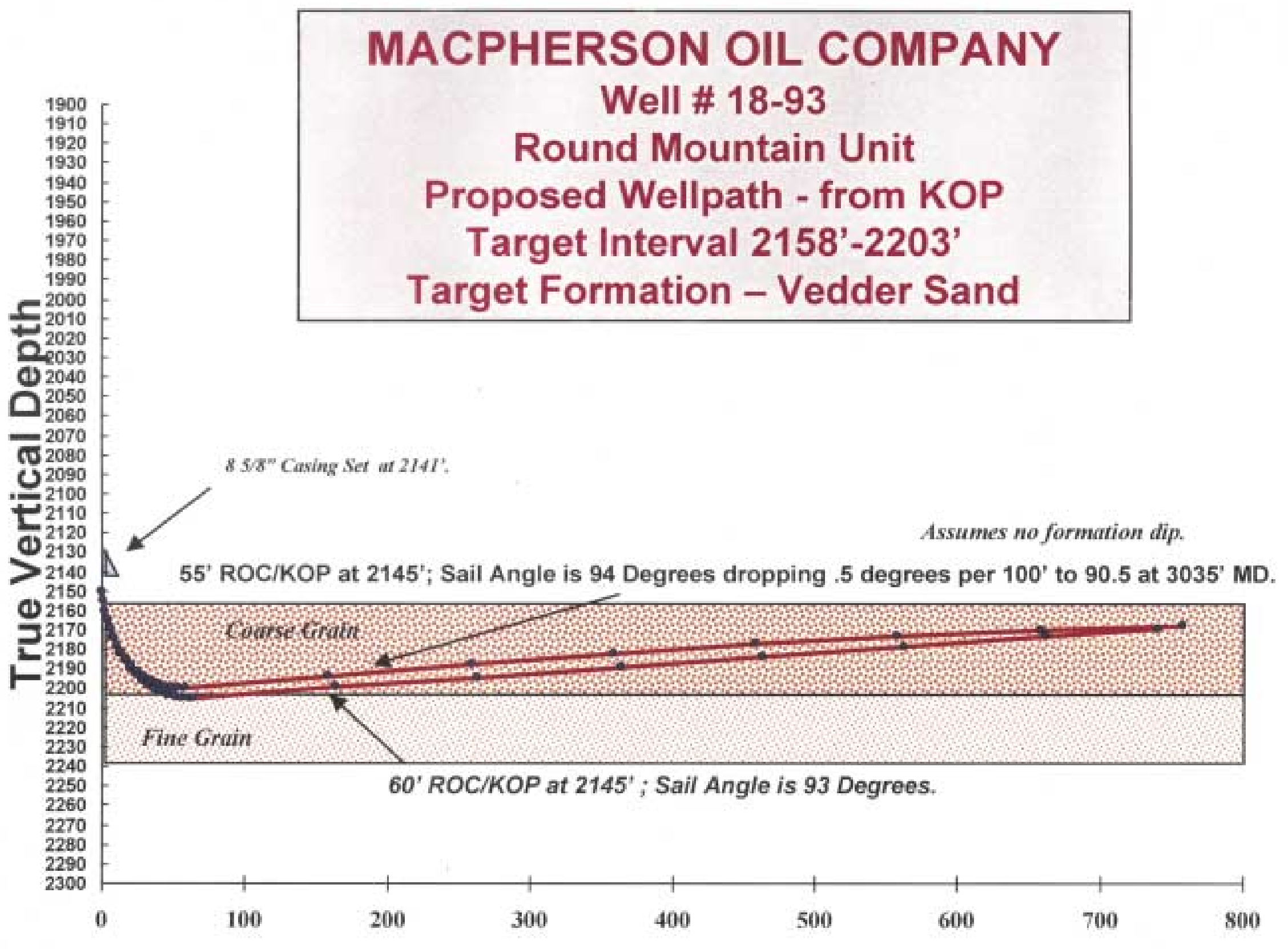

Total Departure 


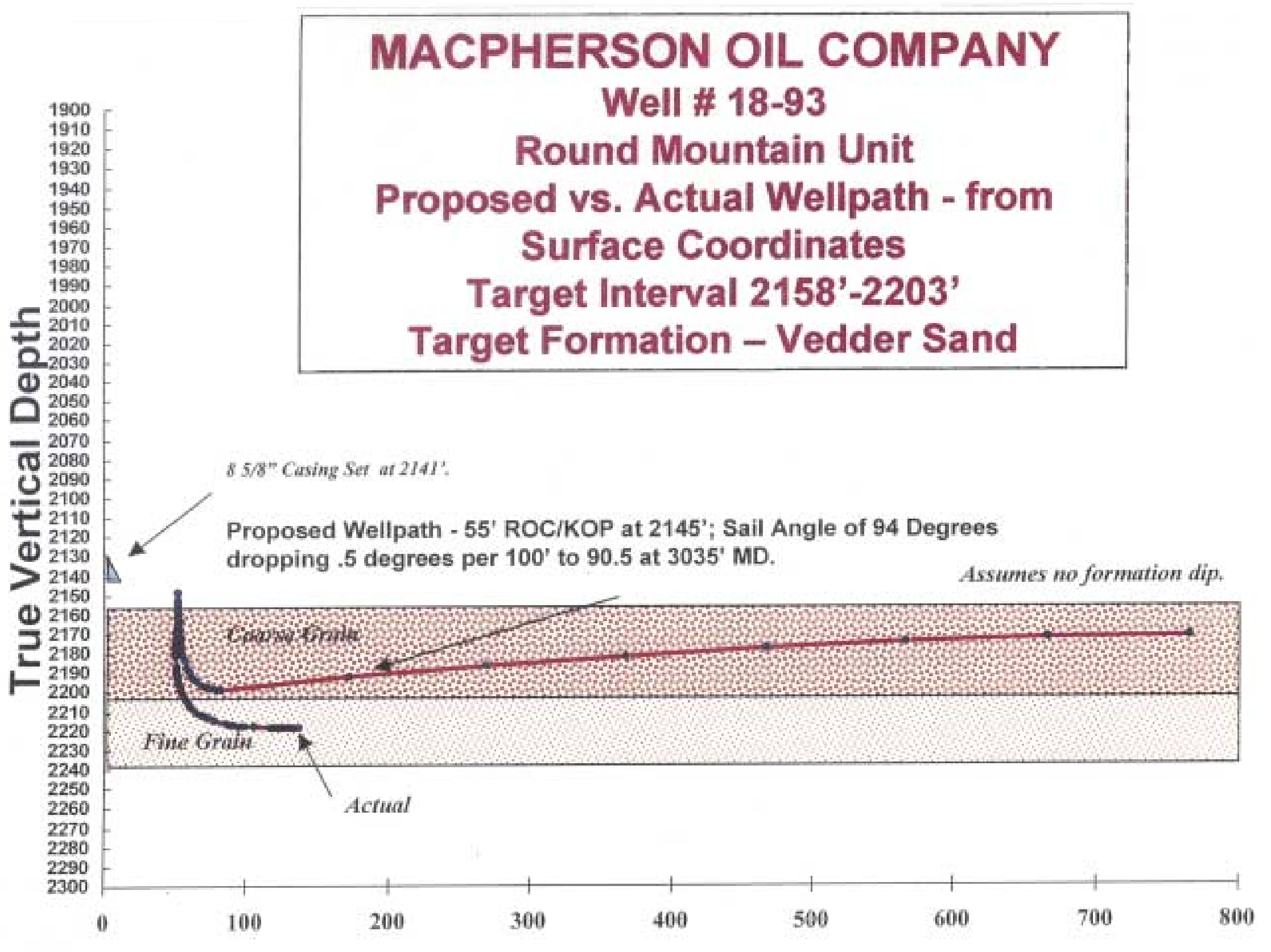

Total Departure 